\title{
Collision-Induced Intramolecular Energy Flow in Highly Excited Toluene
}

\author{
Jongbaik Ree, Kyung Soon Chang, Yoo Hang Kim, and Hyung Kyu Shin ${ }^{\ddagger}$ \\ Department of Chemistrv Education, Chomam National Wniversitv. Grangiu 500-757. Korea \\ ${ }^{\dagger}$ Department of Chemistry and Center for Chemical Dwamics. Inha Chiversirv. Inchon $402-751$. Korea \\ ${ }^{\ddagger}$ Department of Chemistr. Lniversity of Vevada, Reno, Vevada 89557. L.S.A. \\ Received April 4. 2003
}

Key Words : Collision-induced. Intramolecular. Toluene. Ar

The collision-induced relaxation of vibrationally excited molecules has been the subject of continuing interest for the past several decades. ${ }^{1-1+}$ In recent years. furthemore. collisions involving large molecules have been studied actively, revealing valuable information on the rates and the mechanisms of vibrational energy processes. In particular. molecules vibrationally excited to near their dissociation threshold can undergo bond dissociation and vibrational relaxation. processes that play an important role in reaction dynamics. Recent studies ${ }^{3.5-11}$ show that when the excited molecule is a large organic molecule. the average amount of energy transfer per collision is not very large. The average energy. transfer per collision between the highly vibrationally excited benzene and a noble gas atom is known to be about $30 \mathrm{~cm}^{-1}$. which is much smaller than benzene derivatives such as hexafluorobenzene or other hydrocarbons such as toluene and azulene.$^{512-14}$ For example, for hexafluorobenzene + Ar. the measured value of the mean energy transfer per collision by the ultrasiolet absorption method is $-330 \mathrm{~cm}^{-1}$. whereas the calculated value using quasiclassical trajectory methods at $300 \mathrm{~K}$ is $-150 \mathrm{~cm}^{-15}$. For toluene + Ar. the amount of energy transfer is about $-200 \mathrm{~cm}^{-1}$. ${ }^{14}$ These magnitudes are much larger in comparison to results for benzene colliding with argon. Among such large molecules. toluene is a particularly attractive molecule for studying collision-induced intramolecular energy flow and bond dissociation because of the presence of both methyl and ring $\mathrm{CH}$ bonds.

In this paper. as an extension of th previous work in ref. 11. we study the collision-induced dynamics of highly vibrationally excited toluene interacting with argon using quasiclassical trajectory calculations. We now consider the collision sysstem in which one $\mathrm{CH}$ (either $\mathrm{CH}_{\text {methy] }}$ or $\mathrm{CH}_{\text {rng }}$ ) vibration is in a highly excited state and the other in a ground state. while in Ref. 11 we considered both of $\mathrm{CH}_{\text {methy] }}$ and $\mathrm{CH}_{\text {rnge }}$ bonds are in highly excited states. In the latter it was not clear which $\mathrm{CH}$ bond is more effective for collisioninduced inter- and intra-molecular energy transfer in collision with Ar. Thus, we now elucidate which $\mathrm{CH}$ bond is more effective for collision-induced inter- and intra-molecular energy transfer, as considering and comparing the results of inter- and intra-molecular energy transfer dýnamics when

Author to whom conespondence should be addressed. e-mail: jbreelachonnam ac.kr either $\mathrm{CH}_{\text {methy] }}$ or $\mathrm{CH}_{\text {rng }}$ is in highly excited states. Using the results obtained in the calculations. we discuss the relaxation of the excited $\mathrm{CH}$ vibration, and the time evolution of collision-induced intramolecular energy flow from the highly excited $\mathrm{CH}$ vibration. Thus. we elucidate the nature and mechanism of competition between methỵl CH mode and ring $\mathrm{CH}$ mode in transferring energy to the incident atom. We set the initial vibrational energy of the methyl $\mathrm{CH}$ bond or the ring $\mathrm{CH}$ bond equal to the state just $0.10 \mathrm{eV}$ below the dissociation threshold at $300 \mathrm{~K}$.

\section{Interaction Model}

The present work follows the interaction model and numerical procedure. which have already been reported in ref. 11. Briefly: we recapitulate the essential aspects of the
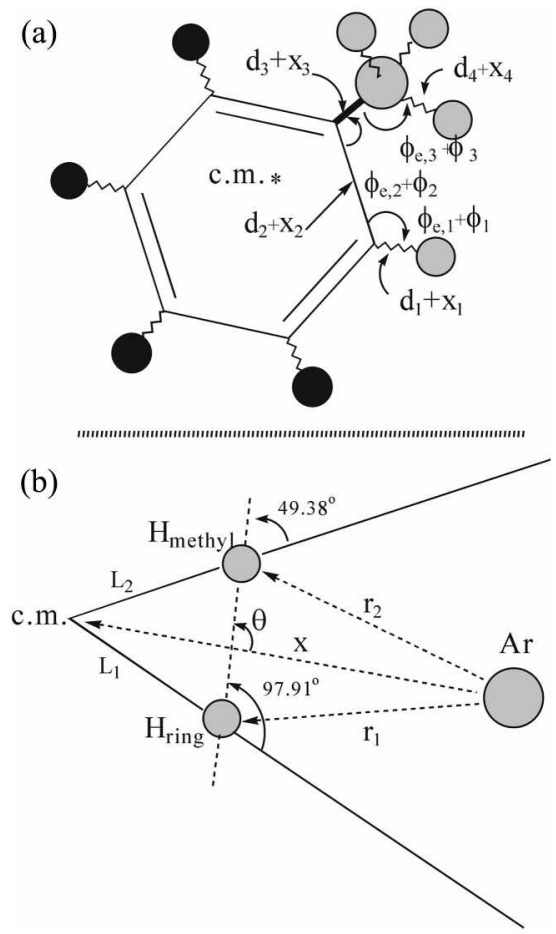

Figure 1. Collision model. (a) The stretching and bending coordinates of vibrations included in the model. The star denotes the center-of-mass $(\mathrm{cm})$ of toluene. (b) The relative coordinate between $\mathrm{Ar}$ and the $\mathrm{cm}$ of toluene ( $\mathrm{A}$ ), the Ar-to- $\mathrm{H}_{\text {nng }}$ distance $\left(\mathrm{r}_{1}\right)$ and the Ar-to- $\mathrm{H}_{\text {methyl }}$ distance $\left(\mathrm{r}_{2}\right)$ are shown. 
interaction of $\mathrm{Ar}$ with toluene in this section. reproducing the collision model in Figure 1 for easy reference. In Figure la. we define all pertinent vibrational modes in the region of toluene in interaction with the incident atom Ar. From the methyl $\mathrm{CH}$ bond to the ring $\mathrm{CH}$ bond. included in the interaction region are the $\mathrm{CH}_{\text {methyl. }} \mathrm{C}-\mathrm{CH}_{3} .(\mathrm{CC})_{\text {ring }}$ and $\mathrm{CH}_{\text {rine }}$ stretches. and the $\mathrm{CCH}_{\text {ntethy, }} \mathrm{CCC}$ and $\mathrm{CCH}_{\text {ringe }}$ bends. where $(\mathrm{CC})_{\text {rine }}$ is the ring's $\mathrm{CC}$ bond linking the methyl group and the $\mathrm{H}_{\text {ring }}$ atom. We consider the interaction of $\mathrm{Ar}$ with a non-rotating toluene. the collision partners lying in the same plane. The overall interaction energy is the sun of the Morse-type intermolecular part. Morse-type intramolecular stretches and the harmonic bends. The first part includes Ar to $\mathrm{CH}_{\text {methy] }}$ and $\mathrm{Ar}$ to $\mathrm{CH}_{\text {ring }}$ interactions. All potential and spectroscopic constants needed in the calculation are listed in ref. 11. From the plot of energy contour around $\mathrm{CH}_{\text {methyl }}$ and $\mathrm{CH}_{\text {rin. }}$. we found that the intermolecular interaction energy surface exhibits a potential well along $\mathrm{Ar}$ approaching the center-of-mass of toluene at the angle $\theta=77^{\circ}$. The angle $\theta$ is measured from the line connecting the hydrogen atoms $\mathrm{H}_{\text {methyl }}$ and $\mathrm{H}_{\text {ring }}$ to the line connecting $\mathrm{Ar}$ and center of mass of toluene as shown in Figure 1. In all collision systems considered here, the incident atom approaches the center of mass of toluene in the $\theta=77^{\circ}$ direction.

We solve the equations of motion for the relative motion. four stretches and three bends using the DIVPAG doubleprecision routine of the IMSL library ${ }^{15.18}$ to describe the time evolution of bond distances. angles. and vibrational energies. as well as the relative coordinate for the model system. We sample 10000 trajectories for each run at $300 \mathrm{~K}$. where the sampling includes determining collision energies chosen from the Maxwell distribution. The initial vibrational phases and displacements are chosen from microcanonical ensembles with the total vibrational energy constant. The initial separation between the center of mass of toluene and $A r$ is set as $13 \AA$ and trajectories are terminated when the separation reaches $15 \dot{A}$ after they passed through the closest distance of approach. The integration step is set as $0.169 \mathrm{fs}$. which is one-tenth the period of the largest frequency. the ring $\mathrm{CH}$ vibration, and is small enough to conserve the total energy. The initial vibrational energy of the excited $\mathrm{CH}$ bond is set to $0.10 \mathrm{eV}$ below its dissociation threshold. which is $3.9717 \mathrm{eV}$ for the $\mathrm{CH}_{\text {methyl }}$ bond and $4.9569 \mathrm{eV}$ for the $\mathrm{CH}_{\text {ring }}$ bond. Thus. for the highly excited $\mathrm{CH}_{\text {methyl, }}$ the initial vibrational energy is $D_{\text {CHmethyl }}-0.1000$ $\mathrm{eV}=3.8717 \mathrm{eV}$ or $31230 \mathrm{~cm}^{-1}$ above the bottom of the potential well. For the highly excited $\mathrm{CH}_{\text {ring }}$ bond the initial vibrational energy $D_{\text {CHring }}-0.1000 \mathrm{eV}=39170 \mathrm{~cm}^{-1}$. In calculating energy transfer from the molecule to Ar. i.e., the deexcitation of $\mathrm{CH}_{\text {methy] }}$ (or $\mathrm{CH}_{\text {ring }}$ ). we measure the initial vibrational energy in excess of the zero point. in which case. the energy values for $\mathrm{CH}_{\text {methyl }}$ and $\mathrm{CH}_{\text {ring }}$ are 29700 and $37600 \mathrm{~cm}^{-1}$. respectively. which can be identified as the initial total energy content of toluene $E_{\mathrm{T}}$. In each collision system we set either $\mathrm{CH}_{\text {methyl }}$ or $\mathrm{CH}_{\text {ring }}$ to this high-energy state. while all other vibrational modes are in their ground states.

\section{Results and Discussion}

We first consider the collision system in which the $\mathrm{CH}_{\text {methyl }}$ vibration is highly excited (i.e., $E_{\mathrm{T}}$ is $29700 \mathrm{~cm}^{-1}$ ), while the ring $\mathrm{CH}$ and all other modes are in their ground states: we shall refer to this as system (i). Then. we consider the case in which the ring $\mathrm{CH}$ vibration is highly excited (i.e., $E_{\mathrm{T}}$ is $37600 \mathrm{~cm}^{-1}$ ), while the methyl $\mathrm{CH}$ and all other modes are in their ground states. and we shall refer it as system (ii). It should be noted that we now consider the collision system in which one $\mathrm{CH}\left(\mathrm{CH}_{\text {methy] }}\right.$ or $\left.\mathrm{CH}_{\text {ring }}\right)$ vibration is in a highly excited state and the other in a ground state, while in ref. 11 we considered both $\mathrm{CH}_{\text {mechyl }}$ and $\mathrm{CH}_{\text {ring }}$ bonds are in highly excited states.

For systems (i) and (ii). the amounts of ensemble-averaged energy transfer for all nondissociative trajectories are $\langle\Delta E\rangle$ $=-298 \mathrm{~cm}^{-1}$ and $-25.5 \mathrm{~cm}^{-1}$. respectively. Here, a negative number represents the molecule losing energy to $\mathrm{Ar}$ via V $\rightarrow$ $\mathrm{T}$ pathway. These values are only 1.0 and $0.068 \%$ of $E_{\mathrm{T}}$. When both $\mathrm{CH}_{\text {mathyl }}$ and $\mathrm{CH}_{\text {ring }}$ bonds are in highly excited states, that is, $0.1 \mathrm{eV}$ below their respective dissociation thresholds (namely, $29700 \mathrm{~cm}^{-1}$ for $\mathrm{C} \cdot \mathrm{H}_{\text {mechyl }}$ and $37600 \mathrm{~cm}^{-1}$ for $\mathrm{C}-\mathrm{H}_{\text {ring }}$ ), the amount of ensemble-averaged energy transfer for all nondissociative trajectories is $-694 \mathrm{~cm}^{-1}$ and energy loss for this highly excited toluene was also only about $1 \%$ of $E_{\mathrm{T}}{ }^{11}$

The amount of energy lost by $\mathrm{CH}_{\text {methyl }}$ is more than ten times that lost by $\mathrm{CH}_{\text {ring. }}$. Thus, the highly excited $\mathrm{CH}_{\text {methyl }}$ shows a much greater tendency of transferring its vibrational energy to translation than the highly excited $\mathrm{CH}_{\text {ring }}$ does. If we approximate the $\mathrm{Ar}-\mathrm{CH}_{\text {ring }}$ interaction in toluene as a representation of the $\mathrm{Ar}-\mathrm{CH}$ interaction in benzene, the nearly 10 to $\mathrm{l}$ ratio of energy transfer efficiency of $\mathrm{CH}_{\text {methyl }}$ to $\mathrm{CH}_{\text {ring }}$ found in the present study is in general agreement with energy transfer experiments for toluene and benzene ${ }^{5.13,13,19}$ However, it is important to note that the above comparison between the ensemble-averaged energy transfer for all nondissociative trajectories for $\mathrm{Ar}-\mathrm{CH}_{\text {methyl }}$ and for Ar-CH $H_{\text {ring. }}$ i.e. $\langle\Delta E\rangle=-298 \mathrm{~cm}^{-1}$ versus $-25.5 \mathrm{~cm}^{-1}$. is made for their $\mathrm{CH}$ bonds initially having their vibrational energies below the dissociation threshold by $0.10 \mathrm{eV}$. Thus. the $\mathrm{CH}$ bonds have unequal amounts of $E_{\mathrm{T}}$. namely: 29700 $\mathrm{cm}^{-1}$ versus $37600 \mathrm{~cm}^{-1}$.

To expand this discussion of the collisional deexcitation of toluene. we now repeat the above calculations for $\mathrm{CH}_{\text {methyl }}$ and $\mathrm{CH}_{\text {ing }}$ with the same initial energy content. For this purpose. we take $E_{\mathrm{T}}=24000 \mathrm{~cm}^{-1}$ that has been considered in previous studies. ${ }^{5.14}$ For this initial energy content. we obtain the ensemble- averaged energy transfer $\langle\Delta E\rangle=-80$.1 and $-34.7 \mathrm{~cm}^{-1}$ for $\mathrm{CH}_{\text {methyl }}$ and $\mathrm{CH}_{\text {ring. }}$. respectively. These results indicate that when $E_{\mathrm{T}}$ is lowered to $24000 \mathrm{~cm}^{-1}$, the energy lost by the excited ring $\mathrm{CH}$ increases somewhat but that by the excited methyl $\mathrm{CH}$ decreases significantly: However, the magnitude of $\langle\Delta E\rangle$ for $\mathrm{CH}_{\text {mecthyl }}$ is still much larger than that for $\mathrm{CH}_{\text {ring }}$ even at this low $E_{\text {T. }}$ The calculated value of $\langle\Delta E\rangle$ for $\mathrm{CH}_{\text {methyl }}$ is smaller than those reported in earlier papers. e.g. $\langle\Delta E\rangle=-125 \mathrm{~cm}^{-1}$ at $E_{\mathrm{T}}=20000 \mathrm{~cm}^{-1}$ la 

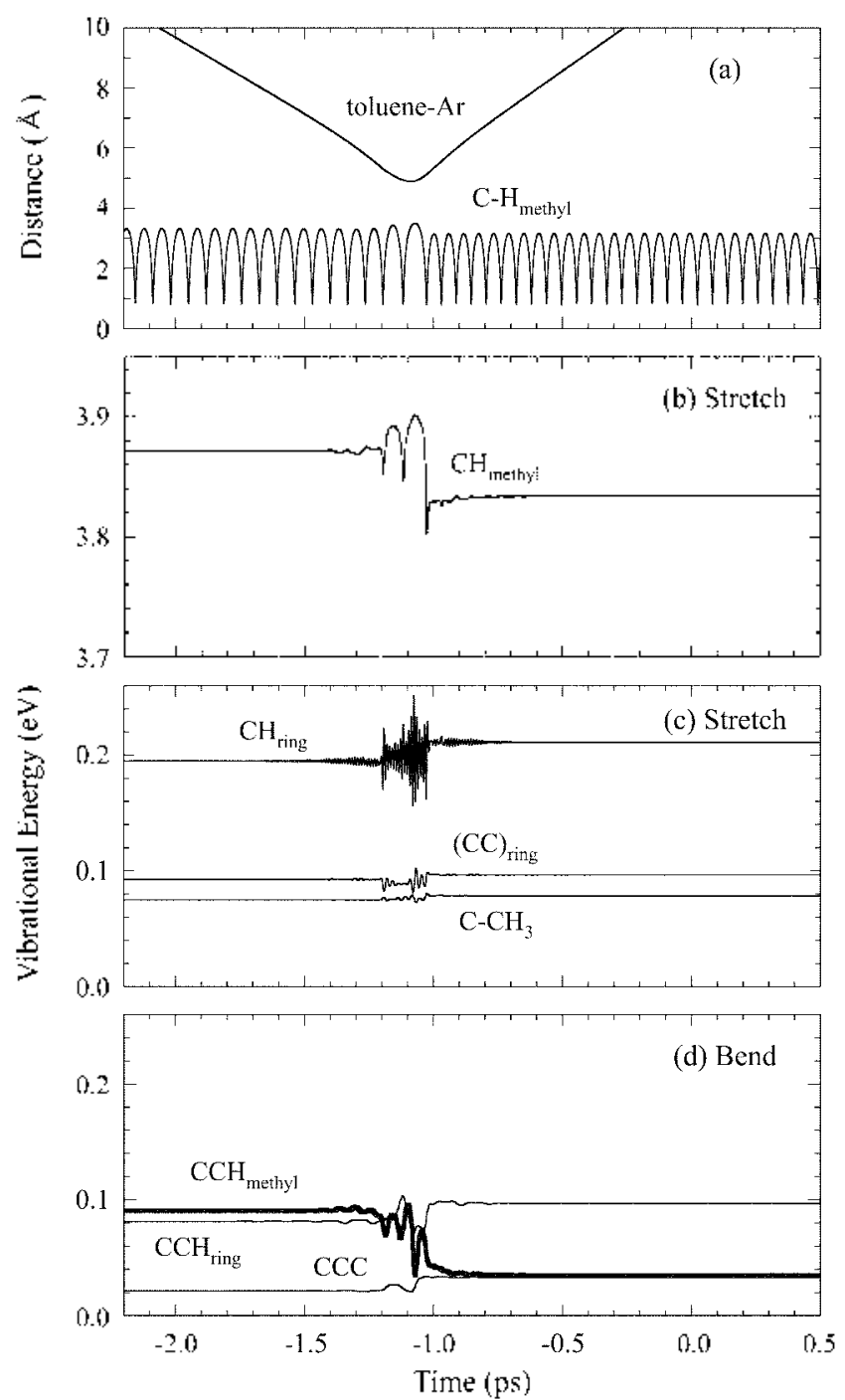

Figure 2. Time evolution of the trajectory representing nondissociative events with the highly excited $\mathrm{CH}_{\text {methyl }}$ system (i). (a) Collision and $\mathrm{CH}_{\text {tnettry' }}$ bond trajectories. (b) The vibrational energy of highly excited $\mathrm{CH}_{\text {nothy] }}$ stretch. (c) The vibrational energies of ground state $\mathrm{CH}_{\text {ring, }}\left(\mathrm{CC}\right.$ ) ring and $\mathrm{C}-\mathrm{CH}_{3}$ stretches. (d) The vibrational energies of ground state $\mathrm{CCH}_{3 n+t h s,} \mathrm{CCH}_{31}$ and $\mathrm{CCC}$ bends. The $\mathrm{CCH}_{\text {tnethy }}$ curve is shown in a heavy line for convenience.

and $-120 \mathrm{~cm}^{-1}$ at $E_{\mathrm{T}}=24000 \mathrm{~cm}^{-1} .{ }^{14}$ On the other hand $\langle\Delta E\rangle$ for $\mathrm{CH}_{\text {ring }}$ is very close to the value of $-33 \mathrm{~cm}^{-1}$ for benzene $\mathrm{CH}$ at $E_{\mathrm{T}}=24000 \mathrm{~cm}^{-1}$ reported by earlier researchers. ${ }^{5}$

Now, we discuss the dynamics of relaxation processes by calculating time evolution of the trajectories. ${ }^{11.17 .18}$ In Figure 2a. we show the toluene-Ar distance (i.e. the collision trajectory) and the $\mathrm{C}-\mathrm{H}_{\text {methyl }}$ bond distance (i.e. . bond trajectory) for the highly excited methyl $\mathrm{CH}$ system. system (i). This representative trajectory is for the collision with energy $0.0367 \mathrm{eV}$. which is fairly close to $3 / 2 k T=0.0388$ $\mathrm{eV}$. The initially highly excited $\mathrm{CH}_{\text {methyl }}$ bond vibrates at the frequency $484 \mathrm{~cm}^{-1}$ and then blue-shifts to $558 \mathrm{~cm}^{-1}$ after collision. The closest distance that $\mathrm{Ar}$ can reach toward the center of mass of toluene is $5 \dot{A}$ occurring near $t=-1.1 \mathrm{ps}$. Closest distances for all trajectories in the toluene-Ar collision in the present study lie between 4 and $8 \mathrm{~A}$. the lower limit being close to the average minimal distance of $3.08 \AA$ by Benshtein and Oref ${ }^{2 i j}$ Since the slope of the collision trajectory changes only slightly it is difficult to identify the time at which the collision begins and that at which it ends. However, the variation of the time evolution of vibrational energies, especially the $\mathrm{CH}_{\text {methyl }}$ energy shown in Figure $2 b$, clearly shows when the collision begins and ends. From the variation of the energy curve in Figure $2 b$, we find that the collision begins at $-1.45 \mathrm{ps}$ and completes at $-0.75 \mathrm{ps}$. so the duration of collision is $0.70 \mathrm{ps}$. which is close to $0.6 \mathrm{ps}$ reported by Bernshtein and Oref in their trajectory calculations. ${ }^{21}$ However. a sharp decrease in the vibrational energy over a short period, where the vibrational energy varies with two large amplitudes, indicates that the essential part of relaxation of the highly excited $\mathrm{CH}_{\text {methyl }}$ is over within $0.2 \mathrm{ps}$, which is much shorter than the duration of collision. When both $\mathrm{CH}_{\text {methyl }}$ and $\mathrm{CH}_{\text {ring }}$ bonds are in highly excited states, the ensemble-averaged time scale for the relaxation of $\mathrm{C} \cdot \mathrm{H}_{\text {methyl }}$ is $0.23 \mathrm{ps}^{.1}$ which is almost the same as the present case. that is, only the $\mathrm{CH}_{\text {methy] }}$ vibration is highly excited. while the ring $\mathrm{CH}$ and all other modes are in their ground states. Comparing the $\mathrm{CH}_{\text {methyl }}$ curve in Figure $2 \mathrm{~b}$ with the collision trajectory in Figure $2 \mathrm{a}$, we note that this short time scale for energy relaxation takes place when a significant amount of acceleration of the collision trajectory occurs before and after tuning the conner of closest approach. ${ }^{2-}$

In Figure $2 \mathrm{~b}$ we note that the initial vibrational energy $3.8717 \mathrm{eV}$ levels off to the final value of $3.8338 \mathrm{eV}$, a relaxation step with $\Delta E=-0.0379 \mathrm{eV}$ or $-305 \mathrm{~cm}^{-1}$. The time evolution for three other stretches is shown in Figure 2c. The $\mathrm{CH}_{\text {ring }}$ stretching mode gains some energy. while both (CC) ring $_{\text {and }} \mathrm{C}-\mathrm{CH}_{3}$ stretches gain only a very small amount of energy. As shown in Figure 2d. while the $\mathrm{CCH}_{\text {ring }}$ and $\mathrm{CCC}$ bends gain energy. the $\mathrm{CCH}_{\text {methy], which is directly }}$ coupled to the $\mathrm{CH}_{\text {methyl }}$ stretch. loses energy. The net energy loss is then carried away by Ar. On the other hand, when both $\mathrm{CH}_{\text {mtechyl }}$ and $\mathrm{CH}_{\text {ring }}$ bonds are in highly excited states. most of the energy lost by C- $\mathrm{H}_{\text {methyl }}$ deposits in the $\mathrm{CCH}_{\text {ring }}$ bend. followed by the $\mathrm{CH}_{\text {ring }}$ stretch and $\mathrm{CCH}_{\text {methy }}$ bend and a small amount is removed by the incident atom. ${ }^{13}$ Thus, the characteristic of the energy transfer for the present case is very different from the former case

The time evolution of the collision event representing system (ii) is considered in Figure 3. Here the collision energy is $0.0362 \mathrm{eV}$. In Figure 3a. the period of the $\mathrm{C}^{-} \mathrm{H}_{\text {ring }}$ vibration varies only slightly on collision, showing that the vibrational frequency of $\mathrm{CH}_{\text {ring }}$ changes from $430 \mathrm{~cm}^{-1}$ to $459 \mathrm{~cm}^{-1}$. The ensemble-averaged energy loss per collision is only $-30.6 \mathrm{~cm}^{-1}$ as shown in Figure $3 \mathrm{~b}$. representing an inefficient relaxation process for the highly excited ring $\mathrm{CH}$. An important difference between systems (i) and (ii) is the duration of collision shown in Figures $2 b$ and $3 b$. From the time evolution of the $\mathrm{CH}_{\text {ring }}$ vibrational energy shown in Figure $3 \mathrm{~b}$. we find the collision beginning at $t=-2.20 \mathrm{ps}$. The Ar- $\mathrm{CH}_{\text {ring }}$ interaction continues for $1.25 \mathrm{ps}$ undergoing sharp oscillations before the $\mathrm{CH}_{\text {rins }}$ vibrational energy levels 

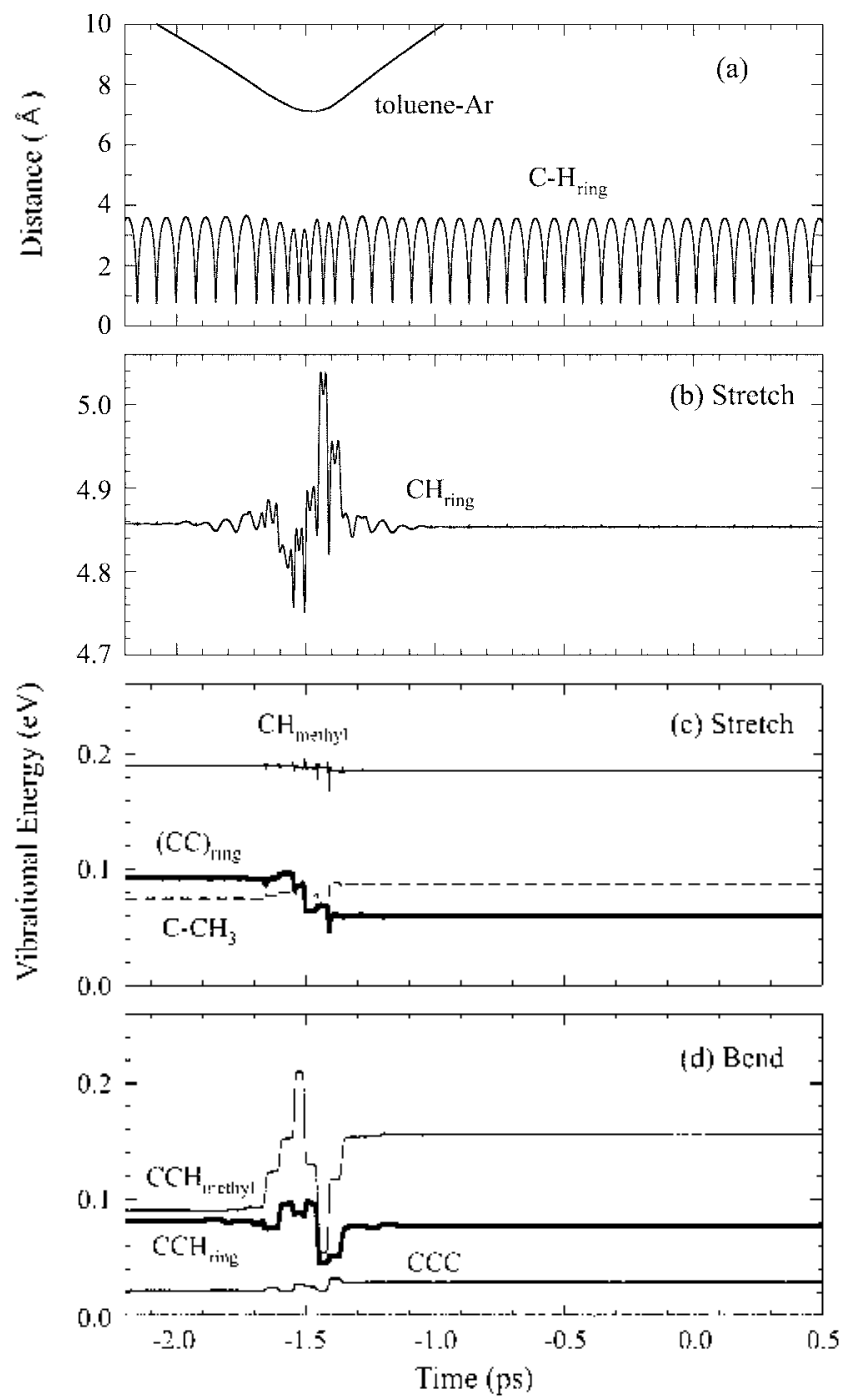

Figure 3. Time evolution of the trajectory representing nondissociative events with the highly excited $\mathrm{CH}_{\text {inu }}$, sy stem (ii) (a) Collision and $\mathrm{CH}_{\text {inu }}$ bond trajectories. (b) The vibrational energy of highly excited $\mathrm{CH}_{\text {ring }}$ stretch. (c) The vibrational energies of ground state $\mathrm{CH}_{\text {mathy }},\left(\mathrm{CC}\right.$ ) ring and $\mathrm{C}-\mathrm{CH}_{3}$ stretches. (d) The vibrational energies of ground state $\mathrm{CCH}_{\text {minthyl, }} \mathrm{CCH}_{\text {tulu and }} \mathrm{CCC}$ bends. The $\mathrm{CCH}_{\text {mrg }}$ curve is shown in a heavy line for convenience.

off to its limiting value. That is. after many energy give-andtake steps. each involving a large amount of energy the $\mathrm{CH}_{\text {rine }}$ bond finally comes out when the collision is over with its vibrational energy nearly unchanged. This situation is markedly different from the $\mathrm{CH}_{\text {methyl }}$ case where fewer energy give-and-take steps (two steps in the representative trajectory shown in Figure 2b) lead to a larger energy transfer. Such energy give-and-take steps are particularly prominent in the heavy-light-heavy mass distribution in the impulsive limit. ${ }^{23}$ Although the collision energy is low. such steps appear to manifest in the present sy stems. especially in system (ii). In sysem (i). the methyl ring is bound to a ring carbon thus making the $\mathrm{C}-\mathrm{C}-\mathrm{H}_{m \text { thyl }}$ region more flexible compared to $\mathrm{C}-\mathrm{H}_{\text {ring. }}$ where $\mathrm{H}_{\text {ring }}$ is directly bound to a ring carbon. The rigidity in the latter system contributes to the appearance of a larger number of steps. each representing the $\mathrm{C} \cdot \mathrm{H} \cdots$ Ar impact even though the collision energy is not very high. The mass distribution of 12-1-40 leads to five impacts in the impulsive limit. ${ }^{23}$

As shown in Figure $3 \mathrm{c}$, both $(\mathrm{CC})_{\text {ring }}$ and $\mathrm{CH}_{\text {methyl }}$ stretches lose some energy. while the $\mathrm{C}-\mathrm{CH}_{3}$ stretch gains energy. An interesting situation is that the $\mathrm{CCH}_{\text {methyl }}$ bend which is farther away from the highly excited $\mathrm{CH}_{\text {ring }}$ site now gains energy. while it loses energy in the previous system where the nearby $\mathrm{CH}_{\text {methy] }}$ is highly excited (see Figure $3 \mathrm{~d}$ ). That is. the $\mathrm{CCH}_{\text {ring }}$ bend directly coupled to the highly excited $\mathrm{CH}_{\text {ring }}$ loses energy as $\mathrm{CCH}_{\text {methyl }}$ coupled to the highly excited $\mathrm{CH}_{\text {methy] }}$ does in the previous system. We note that the closest distance of approach for this representative trajectory is nearly $7 \AA$, which is significantly larger than that shown in Figure $2 \mathrm{a}$.

Acknowledgments. The 4th Supercomputing Application Supporting Program of the Korea Institute of Science and Teclunology Information supported part of the computational time of this work. Y. H. K. gratefully acknowledges the financial supports from the Korea Research Foundation (Grant No. KRF-2001-015-DP0242), and the Brain Korea 21 Project in 2003.

\section{References}

1. Yardley. I. T. Introdhction to Holecular Energy transfer: Academic: New York. 1980.

2. Ree. J. Bull Kowan Chem. Soc. 1993. 14. 47.

3. Lim K. F. J. Chem. Plns. 1994. 101,8756.

4. Orr. B. In Adrances in Iibrational Energv Transfer Inolving Large and Sinall Molectles. Vol. 2A: IAI Press: Greenwich. CT. 1995: pp 21-74.

5. Letizer. T.: Luther. K.: Troe. J.: Gilbert. R. G.: Lim. K. F. J. Chent Phus. 1995, 103, 626 .

6. Wright, S. M. A.: Sims, I. R; Smith. I. W. M. J. Phys. Chem At 2000. 104,10347 .

7. Shin. H. K. J. Phys Chent A 2000. 104. 6699.

8. Kim. Y. H. Bull. Korean Chent Sa. 2000.21 .493$.

9. Hong. J.: Kim. D.: Paeng. K. Bull. Korean Chent. Soc. 2000. 21.785.

10. Nilsson, D.: Nordholm. S. J. Chem. Plys. 2002. 116.7040.

11. Ree. J.: Kim, Y. H.; Shin. H. K. J. Chem. Plns. 2002. 116, 4858.

12. Yerram, M. L.; Brenner, J. D.; King, K. D.: Barker. J. R. J. Phus. Chent 1990. 94.6341.

13. Damm. M.: Hippler. H.: Olschewski. H. A.: Troe. T.: Willner. J. Z. Phis Chem. N.F 1990. 166. 129.

14. Toselli. B. M.: Brenner, J. D.; Yerram. M. L.: Chin. W. E:; King. K. D.; Barker, J. R. J. Chem. Plys. 1991. 95. 176.

15. Gear. C. W. Kumerical Initial Lalue Problems in Ordinan Differential Equations; Prentice-Hall: New York. 1971.

16. MATHLIBRARY. Fortat Sithontines for Mathentatical Applications; IMSL: Houston. 1989: $\mathrm{p} 640$.

17. Ree. J.; Chang. K. S.: Moon, K. H.; Kim. Y. H. Bull. Konan Chem. Soc. 2001, 22. 889.

18. Ko, Y.: Ree. J.: Kim, Y. H.: Shin. H. K. Bull. Korean Chem. Soc 2002. 23.1737.

19. Brenter. T. D.: Erinjeri. T. P.: Barker. T. R. Chent. Phys. 1993. 175. 99.

20. Bernshtein, V.: Oref. I. Chem. Plws. Lett. 1995, 233, 173.

21. Bernshtein, V: Oref, I. J. Chem. Phus, 1995, 104. 1958:; Bernshtein, V.: Lim. K. F.: Oref, I. J. Plys. Chem. 1995, 99. 4531.

22. Tully. T. C. J. Chent Phs 1980. 73.6333.

23. Shit1. H. K. J. Chem. Pho 1975.62.4130 